Pustaka Karya: Jurnal Ilmiah Ilmu Perpustakaan dan Informasi Vol. 9 No. 1, Juni 2021, Hal. 1-8

http://dx.doi.org/10.18592/pk.v9i1.5141

ISSN (p) : 2089-5216 | ISSN (e) : 2723-7699

\title{
Perpustakaan digital berdasarkan perspektif Lucy A. Tedd dan Andrew Large (studi kasus di Perpustakaan Fakultas Teknik UGM Yogyakarta) ${ }^{1}$ Hayatuddiniyah \\ ${ }^{1}$ Program Studi Ilmu Perpustakaan Fakultas Adab dan Ilmu Budaya \\ ${ }^{1}$ Jl. Laksda Adisucipto, Papringan, Caturtunggal, Kec. Depok, Kabupaten Sleman, Daerah Istimewa \\ Yogyakarta 55281 \\ Email : ${ }^{1}$ hayatuddiniyahfz@gmail.com
}

\begin{abstract}
This study aims to determine the digital library based on the perspective of Lucy A. Tedd and Andrew Large at the Library of the Faculty of Engineering, UGM Yogyakarta. This research uses qualitative research methods with the type of case study research. Data collection techniques using observation, interviews, and documentation. The theory used is the perspective of Lucy A. Tedd and Andrew Large. Data analysis in this study uses the Miles \& Huberman model, namely data reduction, data presentation, and drawing conclusions. First, the Library of the Faculty of Engineering UGM Yogyakarta fulfills the process of searching for user information, secondly the fulfillment of the collection of the Library of the Faculty of Engineering UGM Yogyakarta which consists of data and metadata that are interconnected both internally and externally, thirdly, the fulfillment of integration or relationship between the Library of the Faculty of Engineering UGM Yogyakarta and other institutions. or other organizations. At the end of the research, it is suggested to be able to do a network of cooperation to meet the information needs of users. In addition, it can also improve the quality of providing library services to users. The result of this research is that the UGM Yogyakarta Faculty of Engineering Library is a digital library, this is evidenced by the fulfillment of three characteristics of a digital library based on the perspective of Lucy A. Tedd and Andrew Large.
\end{abstract}

Keywords: digital library; lucy a. tedd dan andrew large; the library of faculty engineering ugm yogyakarta

\begin{abstract}
ABSTRAK
Penelitian ini bertujuan untuk mengetahui perpustakaan digital berdasarkan perspektif Lucy A. Tedd dan Andrew Large di Perpustakaan Fakultas Teknik UGM Yogyakarta. Penelitian ini menggunakan metode penelitian kualitatif dengan jenis penelitian studi kasus. Teknik pengumpulan data menggunakan observasi, wawancara, dan dokumentasi. Teori yang dipakai adalah perspektif Lucy A. Tedd dan Andrew Large. Analisis data dalam penelitian ini menggunakan model Miles \& Huberman, yakni reduksi data, penyajian data, dan penarikan kesimpulan. Pertama, pada Perpustakaan Fakultas Teknik UGM Yogyakarta terpenuhi proses pencarian informasi pemustaka, kedua terpenuhinya koleksi Perpustakaan Fakultas Teknik UGM Yogyakarta yang terdiri dari data dan metadata yang saling berhubungan baik dari sisi internal maupun eksternal, ketiga terpenuhinya integrasi atau hubungan Perpustakaan Fakultas Teknik UGM Yogyakarta dengan institusi atau organisasi yang lain. Akhir penelitian disarankan untuk dapat melakukan jejaring kerja sama untuk memenuhi kebutuhan informasi pengguna. Selain itu juga dapat meningkatkan kualitas pemberian layanan perpustakaan kepada pemustaka. Hasil dari penelitian ini adalah Perpustakaan Fakultas Teknik UGM Yogyakarta merupakan perpustakaan digital, ini dibuktikan dengan terpenuhinya tiga karakteristik perpustakaan digital berdasarkan perspektif Lucy A. Tedd dan Andrew Large.
\end{abstract}

Kata Kunci: lucy a. tedd dan andrew large; perpustakaan digital; perpustakaan fakultas teknik ugm yogyakarta 


\section{PENDAHULUAN}

Perpustakaan menurut Sulistyo-Basuki (Basuki, 1991) merupakan sebuah gedung atau bagian dari gedung itu sendiri yang digunakan untuk menyimpan banyak koleksi di dalamnya seperti buku dan terbitan lainnya. Namun perpustakaan tidak dapat dipahami jika hanya dikatakan sebuah gedung yang digunakan untuk menyimpan koleksi saja. Akan tetapi perpustakaan harus dipahami dengan sistem tertentu untuk mengatur atau menempatkan semua koleksi sebagai sumber informasi sehingga informasi tersebut mudah digunakan kapan saja dan dimana saja. Seiring berkembangnya teknologi informasi maka sebuah perpustakaan dituntut untuk mampu menyediakan segala informasi yang dibutuhkan oleh masyarakat. Perkembangan teknologi informasi ini secara otomatis akan merubah pemikiran masyarakat, yang mana masyarakat ingin serba cepat dan praktis dalam mencari informasi.

Teknologi informasi menurut Haag dan Keen dalam Kadir (Kadir \& Triwahyuni, 2013) merupakan suatu alat yang digunakan untuk membantu dalam sebuah pekerjaan yang berhubungan dengan informasi, baik itu dalam penyebaran informasi maupun dalam proses informasi tersebut. Adapun menurut Sulistyo-Basuki (Basuki, 1991) definisi teknologi informasi merupakan teknologi yang digunakan untuk menyimpan, menghasilkan, mengolah, dan menyebarkan informasi berupa angka, audio, tulisan atau gambar.

Dari kedua pernyataan tersebut sudah jelas bahwa sampai saat ini teknologi informasi tidak bisa lepas dari kehidupan masyarakat, seperti dalam dunia perpustakaan teknologi informasi banyak memberikan dampak positif dan banyak perpustakaan-perpustakaan yang antusias menerapkan teknologi di perpustakaannya, hal ini hanya semata-mata bertujuan untuk memenuhi informasi yang masyarakat butuhkan. Dengan banyaknya perpustakaan yang menerapkan teknologi, maka secara tidak langsung perpustakaan tersebut menyimpan, menghasilkan, mengolah, serta menyebarkan informasi dalam bentuk digital, yang mana dikenal dengan perpustakaan digital.

Perpustakaan digital atau Digital Library menurut Brian Lang dalam Qalyubi (Qalyubi, 2007) merupakan penggunaan tekhnologi digital yang mana berguna untuk memperoleh informasi, menyimpan informasi, melestarikan informasi dan menyebarluaskannya dalam bentuk digital, baik itu dari hasil digitalisasi bentuk tercetak, audio, dan bentuk lainnya. Hal ini bertujuan untuk memberikan kemudahan kepada pengguna untuk mendapatkan informasi secara cepat dan akurat.

Namun, di samping itu perpustakaan digital bukan hanya tentang penyediaan informasi dalam bentuk digital saja, akan tetapi seperti yang diungkapkan oleh The Digital Library Federation dalam definisi perpustakaan digital yang berbunyi: "digital libraries are organizations that provide the resources, including the specialized staff, to select, structure, offer intellectual access to, interpret, distribute, preserve the integrity of, and ensure the persistence over time of collections of digital works so that they are readily and economically available for use by a defined community or set of communities".

Perpustakaan Fakultas Teknik UGM Yogyakarta merupakan salah satu perpustakaan yang menerapkan perpustakaan digital dalam layanannya, yaitu dibuktikan dengan adanya koleksi digital yang dapat di akses melalui laman http://lib.ft.ugm.ac.id/web/. Adapun koleksi digital yang disediakan Perpustakaan Fakultas Teknik UGM Yogyakarta tersebut seperti e-journal, $e$-book dan tugas akhir. Dalam penyediaan koleksi digital tersebut Perpustakaan Fakultas Teknik UGM Yogyakarta bekerja sama dengan Perpustakaan Pusat UGM Yogyakarta. Perpustakaan Fakultas Teknik UGM Yogyakarta juga memanfaatkan media sosial yaitu Instagram dalam menyebarkan informasi, seperti informasi tentang koleksi perpustakaan maupun kegiatan-kegiatan yang sedang 
atau telah diselenggarakan oleh perpustakaan, sehingga ini menjadikan Perpustakaan Fakultas Teknik UGM Yogyakarta memiliki aksesbilitas yang relatif tinggi dalam penyebaran informasi.

Selain itu, pada lantai satu Perpustakaan Fakultas Teknik UGM Yogyakarta terdapat 8 komputer, yang mana komputer tersebut digunakan pemustaka untuk mengakses informasi misalkan tugas akhir dengan full text, akan tetapi jika pemustaka mengakses dengan jaringan luar UGM Yogyakarta maka pemustaka diminta login SSO (Single Sign On) terlebih dahulu. Dengan adanya fasilitas seperti yang telah disebutkan diatas, pustakawan berharap mampu memenuhi kebutuhan pemustakanya. Maka dari itu, penelitian ini bertujuan untuk mengetahui apakah Perpustakaan Fakultas Teknik UGM Yogyakarta tersebut bisa dikatakan sebagai perpustakaan digital atau belum dengan melihat dari karakteristik perpustakaan digital.

Adapun teori yang digunakan adalah teori dari perspektifnya Lucy A. Tedd dan Andrew Large untuk melihat bagaimana karakteristik perpustakaan digital, karena dalam teori Lucy A. Tedd dan Andrew Large tersebut lebih fokus kepada informasi, yang mana informasi merupakan hal yang paling penting dalam sebuah perpustakaan (Tedd \& Large, 2006), baik itu dimulai dari bagaimana informasi tersebut diolah sampai dengan bagaimana informasi-informasi tersebut bisa digunakan dan dimanfaatkan penggunanya.

Dengan kata lain informasi-informasi tersebut dibungkus dengan sebutan koleksi perpustakaan, koleksi perpustakaan tersebut berupa teks, gambar diam atau bergerak, audio, maupun bentuk koleksi lainnya. Hal ini berbeda dengan kebanyakan konsep perpustakaan digital lainnya, yaitu yang lebih fokus kepada keadaan social teknisnya, seperti tentang manajemen dan sistem perangkat lunak yang digunakan. Selain itu, teori Lucy A. Tedd dan Andrew Large ini merupakan teori yang mendasari beberapa karya ilmiah dan buku tentang perpustakaan digital, salah satunya adalah buku perpustakaan digital karya Putu Laxman Pendit.

\section{TINJAUAN PUSTAKA}

Tinjauan pustaka dalam penelitian ini mengambil dari tiga penelitian sebelumnya, yang pertama adalah sebuah Jurnal Imam Bonjol Volume 2 Nomor 1 yang ditulis oleh Nasrul Makdis (2018) yang berjudul "Paradigma Perpustakaan Era Klasik dan Modern (Digital)” (Makdis, 2018), dalam jurnal tersebut bertujuan untuk mengetahui perbedaan antara perpustakaan tradisonal atau yang masih menggunakan sistem manual dengan perpustakaan modern (digital) serta cara pandang dalam melihat kedua era yang berbeda tersebut.

Adapun metode yang digunakan dalam penelitian ini adalah metode kualitatif. Sedangkan hasil dalam penelitian ini yang pertama adalah perubahan paradigma dari perpustakaan yang menggunakan konsep manual atau tradisonal menjadi perpustakaan modern berbasis teknologi informasi, dan hasil yang kedua adalah pengelolaan perpustakaan dengan cara klasik/tradisional ataupun modern tergantung dari kesiapan Sumber Daya Manusia (SDM) pada perpustakaan itu sendiri, dan ketersediaan dana yang cukup menjadi faktor khusus dalam pengelolaan perpustakaan.

Kedua adalah jurnal yang berjudul "Perpustakaan Digital : Paradigma, Konsep dan Teknologi Informasi yang Digunakan” oleh Imam Yuadi (Yuadi, 2007). Jurnal tersebut bertujuan untuk menghasilkan paradigma riset dan produk yang melayani pengguna dengan kebutuhan informasi yang dilihat dari sisi sosial, hukum, dan ekonomi. Adapun metode yang digunakan dalam penelitian ini adalah metode kualitatif. Sedangkan hasil dalam penelitian ini adalah melihat perpustakaan digital dari konsep perkembangan teknologi informasi yang begitu pesat dengan didukung teknologi komunikasi yang membawa kepada proses pengolahan data berbasis teknologi informasi sehingga secara lebih efektif dan efisien akan menghasilkan produk-produk informasi 
(e-library, e-book, current information service), yang mana produk-produk informasi tersebut termasuk ke dalam kategori perpustakaan digital (digita library).

Ketiga adalah penelitian yang dilakukan oleh Sungadi (2017) yang berjudul "Perubahan Paradigma Perpustakaan” (Sungadi, 2017). Penelitian ini bertujuan untuk mengubah paradigma perpustakaan tradisional menjadi perpustakaan modern berbasis teknologi informasi. Metode yang digunakan dalam penelitian ini adalah metode kualitatif. Adapun hasil dalam penelitian ini adalah perubahan paradigma perpustakaan menjadi perpustakaan berbasis teknologi informasi yang dilihat dari perubahan perpustakaan dalam tiga zaman (era tradisional, era otomasi, dan era digital).

Berdasarkan pemaparan ketiga penelitian di atas, terdapat persamaan dan perbedaan dengan penelitian ini. Persamaannya yaitu terletak pada apa yang diteliti, yaitu meneliti tentang konsep perpustakaan digital dan dengan menggunakan metode kualitatif. Adapun perbedaannya yaitu untuk penelitian yang pertama menggunakan konsep perpustakaan era klasik dan modern, untuk penelitian kedua menggunakan konsep perpustakaan digital dari sisi teknologi informasi, dan untuk penelitian ketiga menggunakan konsep perubahan perpustakaan dalam tiga zaman (era tradisional, era otomasi, dan era digital), sedangkan dalam penelitian ini menggunakan konsep perpustakaan digital Lucy A. Tedd dan Andrew Large.

Lucy A. Tedd dan Andrew Large mengemukakan teori tentang perpustakaan digital dalam bukunya yang berjudul Digital Libraries : Principles and Practice in a Global Environment. Perpustakaan digital berawal dari proses digitalisasi artikel dan jurnal, selanjutnya pada tahun 1990an berbagai macam penelitian tentang perpustakaan digital terus berkembang pesat. Saat ini perpustakaan digital juga banyak didirikan di negara-negara maju dengan didukung teknologiteknologi yang ada, salah satunya adalah The African Digital Library, The African Digital Library bisa diakses seluruh masyarakat yang tinggal di Afrika, The African Digital Library menyediakan berbagai informasi mengenai pendidikan dan pembangunan Afrika dalam bentuk electronic books (e-books), electronic journals (e-journals) dan lain-lain. Lucy A.

Tedd dan Andrew Large memaparkan bahwa perpustakaan digital merupakan perpustakaan yang memiliki kemampuan untuk menciptakan, mencari, dan menggunakan informasi. Perpustakaan digital memiliki koleksi yang mencakup data dan metadata. Perpustakaan digital terintegrasi dengan berbagai institusi atau organisasi lainnya. (Tedd \& Large, 2006)

Berdasarkan karakteristik di atas, yang dimaksudkan dalam poin pertama adalah sebuah perpustakaan bisa dikatakan sebagai perpustakaan digital apabila memiliki kemampuan untuk menciptakan, mencari, dan menggunakan informasi dalam berbagai macam bentuk dalam sebuah jaringan digital, yang mana informasi tersebut tersebar luas dan bersifat bebas, sehingga masyarakat pengguna informasi dapat mengaksesnya secara luas dan bebas. Adapun untuk karakteristik poin kedua adalah perpustakaan digital memiliki koleksi yang mencakup data dan metadata yang saling terhubung dengan metadata lainnya, baik dari sisi internal perpustakaannya maupun dari sisi eksternalnya, yang dimaksudkan dengan sisi internal adalah hanya terhubung di lingkungan perpustakaan yang bersangkutan saja, sedangkan sisi eksternal adalah terhubung dengan lingkungan luar dari perpustakaan yang bersangkutan.

Metadata tersebut menjelaskan suatu data, seperti penulis, judul, tahun publikasi dan lain sebagainya. Pada perpustakaan tradisional metadata disebut dengan informasi bibliografi. Sedangkan pada karakteristik poin ketiga adalah perpustakaan digital memiliki tugas untuk mengoleksi dan mengatur sumber informasi digital yang sedang dikembangkan, dengan tujuan 
untuk memenuhi kebutuhan informasi penggunanya, maka dari itu perpustakaan harus terintegrasi dengan berbagai institusi atau organisasi lainnya, seperti perpustakaan, atau museum, atau arsip, atau sekolah atau unit-unit yang lain yang juga mengoleksi, mengatur, merawat, dan menyediakan informasi secara meluas agar tercapainya tujuan awal yaitu memenuhi kebutuhan informasi penggunanya.

Menurut Pendit (Pendit, 2007) karakteristik poin ketiga merupakan karakteristik yang paling ambisius dalam konsep perpustakaan digital, namun jika dilihat ketiga karakteristik tersebut selalu menekankan adanya integrasi dan keterkaitan karena teknologi digital memungkinkan semua itu terjadi. Selain adanya integrasi dan keterkaitan, kerjasama antar institusi juga harus diperhatikan walaupun tidak tertulis secara eksplisit. Dengan adanya peran teknologi digital dalam proses penerapan perpustakaan digital maka seharusnya perpustakaan digital menjadi institusi yang sangat terbuka karena pemakai jasanya dapat turut campur menentukan keberlangsungan perpustakaan digital tersebut.

\section{METODE PENELITIAN}

Penelitian ini menggunakan metode kualitatif atau disebut juga metode naturalistik karena dalam penelitianini akan menerangkan sudut pandang tentang perpustakaan digital berdasarkan teori Lucy A. Tedd dan Andrew Large di Perpustakaan Fakultas Teknik UGM Yogyakarta sesuai dengan keadaan lapangan yang akan diteliti. Sedangkan jenis penelitian yang digunakan adalah studi kasus (case studies), yang mana studi kasus ialah bagian dari penelitian kualitatif, hal ini sesuai dengan pendapatnya Prof. Dr. Mudjia Rahardjo (Rahardjo, 2010) yang mengatakan bahwa dalam sebuah penelitian kualitatif setidaknya ada 8 jenis, salah satunya adalah Studi Kasus (Case Studies). Alasan penggunaan studi kasus (case studies) disini karena penelitian ini dilakukan terhadap organisasi, dalam hal ini Perpustakaan Fakultas Teknik UGM Yogyakarta, yang mana peneliti akan mendapatkan data melalui teknik observasi, wawancara, dan dokumentasi.

Sumber data yang didapat dalam penelitian ini yang pertama mengunakan sumber data primer yaitu informan yang bersumber dari Pustakawan Perpustakaan Fakultas Teknik UGM Yogyakarta yang mana penentuan informan tersebut menggunakan teknik Purposive Sampling, dan yang kedua menggunakan sumber data sekunder yaitu dokumen-dokumen yang dimiliki oleh Perpustakaan Fakultas Teknik UGM Yogyakarta, baik dalam bentuk catatan, gambar, maupun screenshot sistem. Adapun proses pengumpulan data dalam penelitian ini dilakukan dengan tiga teknik, yaitu observasi (pengamatan) dengan menggunakan jenis observasi terus terang, interview (wawancara) dengan menggunakan jenis wawancara tak berstruktur, dan dokumentasi. Sedangkan untuk analisis data yang digunakan dalam penelitian ini menggunakan model Miles \& Huberman yang memiliki tiga aktivitas, yaitu pertama dimulai dengan reduksi data, lalu kemudian yang kedua adalah penyajian data dan yang terakhir adalah penarikan kesimpulan.

\section{HASIL DAN PEMBAHASAN}

Perpustakaan Fakultas Teknik UGM Yogyakarta merupakan perpustakaan tingkat fakultas yang berada dibawah naungan Fakultas Teknik UGM Yogyakarta. Perpustakaan Fakultas Teknik UGM Yogyakarta berlokasi di Kompleks Universitas Gadjah Mada Yogyakarta, Jalan Grafika No.2, Senolowo, Sinduadi, Mlati, Kabupaten Sleman, Daerah Istimewa Yogyakarta 55284. Perpustakaan Fakultas Teknik UGM Yogyakarta memiliki tiga lantai. Pada lantai satu terdapat ruang kepala perpustakaan, ruang staf, area belajar, dan ruang baca tugas akhir atau disebut dengan ruang ETD (Electronic Theses and Dissertations) yang dapat diakses oleh mahasiswa dalam bentuk digital maupun scan dokumen dan front office, ruang ETD ini dilengkapi dengan beberapa unit komputer yang dapat digunakan mahasiswa untuk mengakses tugas akhir. 
Pada lantai dua terdapat ruang referensi dan ruang sirkulasi, ruang belajar dan diskusi yang juga dilengkapi dengan 12 unit komputer dan 2 buah layar LED yang dapat digunakan mahasiswa untuk kegiatan akademik. Pada lantai 3 terdapat ruang diskusi tertutup, ruang studio mini, dan mushola.

Koleksi yang dimiliki Perpustakaan Fakultas Teknik UGM Yogyakarta terdisi dari koleksi tercetak dan digital. Koleksi tercetak tersebut terdiri dari buku (teknik dan non teknik), jurnal, penelitian, handout kuliah, referensi (kamus, ensiklopedia, dan prosiding), dan majalah ilmiah dan populer. Sedangkan koleksi digital yang dimiliki Perpustakaan Fakultas Teknik UGM Yogyakarta dapat diakses melalui halaman website http://lib.ft.ugm.ac.id/web/ yaitu pada menu koleksi. Pada menu koleksi tersebut mahasiswa dapat mengakses koleksi digital seperti $e$-book, $e$-journal, tugas akhir, dan lain sebagainya.

Selain website utama perpustakaan, Perpustakaan Fakultas Teknik UGM Yogyakarta juga memiliki website Subject Guide yang mana pengguna dapat mengaksesnya di laman http://kit.ft.ugm.ac.id/sp/subjects/, dalam website Subject Guide ini berisi artikel-artikel atau refensi-referensi yang perpustakaan kumpulkan kemudian dikelompokkan berdasarkan topik pada website tersebut, contohnya adalah informasi seperti Academic Skills Guides, Departemen Guides, Topic Guides, dan lain sebagainya.

Perpustakaan Fakultas Teknik UGM Yogyakarta memenuhi tiga karakteristik perpustakaan digital berdasarkan perspektif Lucy A. Tedd dan Andrew Lange, yaitu dalam proses informasi, koleksi perpustakaan dan integrasi perpustakaan dengan institusi atau organisasi yang lain. Pertama untuk proses informasi di Perpustakaan Fakultas Teknik UGM Yogyakarta ini terpenuhi baik dari segi kemampuan menciptakan, mencari, maupun menggunakan informasi. Kemampuan menciptakan informasi di Perpustakaan Fakultas Teknik UGM Yogyakarta ini dibuktikan dengan adanya pembuatan video dan penulisan berita hasil dari kegiatan-kegiatan yang diselenggarakan, baik itu diselenggarakan oleh perpustakaan sendiri maupun dari luar, yang mana disebarluaskan melalui website http://lib.ft.ugm.ac.id/web/ dan http://kit.ft.ugm.ac.id/sp/subjects/.

Sedangkan kemampuan mencari informasi yang dimiliki Perpustakaan Fakultas Teknik UGM Yogyakarta ini yaitu perpustakaan mencari informasi berupa buku, artikel, maupun referensireferensi lainnya sesuai permintaan, biasanya ini adalah permintaan dari mahasiswa selaku user, namun permintaan mahasiswa dalam mencari informasi ini tidak dipublikasikan oleh perpustakaan. Selain itu Perpustakaan Fakultas Teknik UGM Yogyakarta juga mencari informasi berupa artikel-artikel yang nantinya akan ditampilkan di website Subject Guide. Selain itu, dalam kemampuan mencari informasi juga dilakukan perpustakaan dengan mencari informasi melalui OPAC (Online Public Access Catalog), adapun informasi yang dicari berupa informasi tentang koleksi yang dimiliki oleh perpustakaan.

Adapun kemampuan menggunakan informasi pada Perpustakaan Fakultas Teknik UGM Yogyakarta ini yaitu apabila informasi itu berasal dari permintaan mahasiswa maka perpustakaan langsung menggunakannya dengan cara menyebarkannya kepada mahasiswa. Selain itu, apabila perpustakaan menyelenggarakan kegiatan dan dari kegiatan tersebut menghasilkan sebuah video, maka pustakawan atau mahasiswa dapat menggunakan kembali atau dalam hal ini mengakses kembali informasi yang ada di video tersebut kapanpun dibutuhkan, hal ini bertujuan untuk mengingat kembali konten atau materi pada kegiatan yang telah diselenggarakan dan juga sebagai bahan evaluasi untuk kegiatan-kegiatan selanjutnya.

Disamping itu, dalam kemampuan menggunakan informasi ini juga dilakukan perpustakaan dengan menggunakan informasi yang bersumber dari internet atau yang lainnya. Sebagai 
contohnya adalah apabila salah satu pustakawan menemukan informasi dari luar, baik itu bersumber dari internet atau yang lainnya, yang mana informasi tersebut berhubungan dengan perpustakaan atau dianggap penting dan perlu, maka pustakawan yang bersangkutan tersebut akan menggunakannya dengan membagikan informasi tersebut kepada pustakawan yang lainnya, kegiatan ini bertujuan agar dapat digunakan oleh pustakawan yang lain sesuai kebutuhannya.

Kedua adalah koleksi yang dimiliki Perpustakaan Fakultas Teknik UGM Yogyakarta juga terpenuhi, yang mana koleksinya terdiri dari data dan metadata yang saling berhubungan, dari sisi internal maupun eksternal. Hal ini dapat dibuktikan dengan aksesbilitas yang relatif tinggi dalam penyebaran informasi (koleksi), sebagai contoh mahasiswa Fakultas Teknik UGM Yogyakarta dapat mengakses koleksi yang ada di Perpustakaan Pusat UGM atau Perpustakaan Fakultas lainnya dengan mudah, karena data-data koleksi atau database disini saling berhubungan atau saling terintegrasi, yaitu tidak hanya internal Fakultas Teknik saja, tapi juga eksternal Fakultas Teknik. Selain itu, koleksi Perpustakaan Fakultas Teknik UGM Yogyakarta terdiri dari metadata yaitu berupa data bibliografinya seperti judul, pengarang, tahun, ISBN, abstrak, jumlah halaman dan lain-lain. Hal ini dapat dilihat melalui penelusuran koleksi pada OPAC (Online Public Access Catalog) perpustakaan dan atau pada repository ETD (Electronic Theses and Dissertations).

Ketiga adalah integrasi yang dimiliki Perpustakaan Fakultas Teknik UGM Yogyakarta dengan institusi atau organisasi yang lain juga terpenuhi. Integrasi Perpustakaan Fakultas Teknik UGM Yogyakarta ini yaitu dengan Perpustakaan Pusat UGM atau Perpustakaan Fakultas maupun Perpustakaan Departemen lainnya yang masih berada dalam lingkungan UGM. Akan tetapi, Perpustakaan Fakultas Teknik UGM Yogyakarta tidak memiliki integrasi atau hubungan dengan perpustakaan di luar lingkungan UGM maupun dengan kearsipan atau museum atau sekolah atau unit-unit lainnya, hal ini disebabkan karena Perpustakaan Fakultas Teknik UGM Yogyakarta berada di bawah naungan Fakultas Teknik, maka dari itu yang dapat melakukan hubungan atau bentuk kerja sama dengan institusi atau organisasi di luar dari lingkungan UGM hanyalah Fakultas, Departement, maupun Universitas saja.

Perpustakaan Pusat UGM Yogyakarta memiliki 9 jaringan kerja sama, salah satunya adalah jaringan kerja sama dengan Anti-Corruption Clearing House (Portal Pengetahuan Anti Korupsi). Jaringan kerja sama ini dapat dilihat pada halaman utama website Perpustakaan Pusat UGM Yogyakarta yaitu pada menu jejaring. Maka dari itu, karena Perpustakaan Fakultas Teknik UGM Yogyakarta terintegrasi dengan Perpustakaan Pusat UGM Yogyakarta maka Perpustakaan Fakultas Teknik UGM Yogyakarta juga dapat menjangkau kerjasama tersebut, namun tidak secara langsung akan tetapi harus melewati proses dengan Perpustaan Pusat UGM Yogyakarta terlebih dahulu.

\section{KESIMPULAN}

Perpustakaan Fakultas Teknik UGM Yogyakarta sudah sepenuhnya memenuhi karakteristik perpustakaan digital berdasarkan perspektif Lucy A. Tedd dan Andrew Lange. Karakteristik pertama yaitu terpenuhinya proses informasi yang ada di perpustakaan, baik dari kemampuannya untuk menciptakan informasi, mencari informasi dan menggunakan informasi. Karakteristik kedua yaitu terpenuhinya koleksi perpustakaan yang terdiri dari data dan metadata. Karakteristik ketiga yaitu integrasi perpustakaan dengan institusi / organisasi yang lain juga terpenuhi.

Oleh karena itu, dapat ditarik kesimpulan bahwa Perpustakaan Fakultas Teknik UGM Yogyakarta merupakan perpustakaan digital, karena tiga karakteristik perpustakaan digital yang dikemukakan berdasarkan perspektif Lucy A. Tedd dan Andrew Large terpenuhi di Perpustakaan Fakultas Teknik UGM Yogyakarta, baik itu dilihat dari proses informasi, koleksi perpustakaan, maupun 
integrasi yang dimiliki perpustakaan dengan lembaga yang lain. Adapun saran untuk dapat menjadi bahan pertimbangan maupun bahan evaluasi bagi Perpustakaan Fakultas Teknik UGM Yogyakarta adalah agar dapat melakukan jejaring kerja sama dengan berbagai lembaga atau organisasi lainnya di luar lingkungan UGM, hal ini bertujuan untuk memenuhi kebutuhan informasi pengguna dalam mengakses informasi, yang mana informasi tersebut tersedia secara luas, lengkap dan beragam. Selain itu juga dapat meningkatkan kualitas pemberian layanan perpustakaan kepada pemustaka.

\section{DAFTAR PUSTAKA}

Basuki, S. (1991). Pengantar ilmu perpustakaan. Gramedia Pustaka Utama. https://books.google.co.id/books?id=3GeZAAAACAAJ

Digital Library Federation . 2004 . “A Working Definition of Digital Library [1998]”, dalam https://old.diglib.org/about/dldefinition.htm,

Kadir, A., \& Triwahyuni, T. C. (2013). Pengantar teknologi informasi edisi revisi. Yogyakarta: Andi Offset.

Makdis, N. (2018). PARADIGMA PERPUSTAKAAN ERA KLASIK DAN MODERN

(DIGITAL). Jurnal Imam Bonjol: Kajian Ilmu Informasi dan Perpustakaan, 2(1), 89-93.

Pendit, P. L. (2007). Perpustakaan Digital: Perspektif Perpustakaan Perguruan Tinggi Indonesia. Sagung Seto.

Qalyubi, S. (2007). Dasar-dasar ilmu perpustakaan dan informasi. Yogyakarta: Jurusan Ilmu Perpustakaan dan Informasi (IPI), Fakultas Adab UIN Sunan Kalijaga.

Rahardjo, M. (2010). Jenis dan metode penelitian kualitatif. Tersedia secara online di: http://mudjiarahardjo. com/materi-kuliah/215-jenis-dan-metode-penelitian-kualitatif. html [diakses di Jakarta, Indonesia: 15 Juni 2015].

Sungadi, S. (2017). Perubahan Paradigma Perpustakaan. Buletin Perpustakaan, 57, 11-26.

Tedd, L. A., \& Large, A. (2006). Digital Libraries: Principles and Practice in a Global Environment. Webology, 3(1), 1-2.

Yuadi, I. (2007). Perpustakaan digital: Paradigma, konsep dan teknologi informasi yang digunakan. Jurnal Jurusan Ilmu Informasi dan Perpustkaan FISIP UnairSurabaya, 2835. 